\title{
Personalized Cardiovascular Regenerative Medicine: Targeting the Extreme Stages of Life
}

\author{
Paolo Madeddu ${ }^{1 *}$, Elisa Avolio ${ }^{1}$, Valeria Vincenza Alvino ${ }^{1}$, Marianna Santopaolo ${ }^{1}$ and \\ Gaia Spinetti ${ }^{2}$ \\ ${ }^{1}$ Translational Health Sciences, Bristol Heart Institute, Bristol Royal Infirmary, University of Bristol, Bristol, United Kingdom, \\ ${ }^{2}$ Laboratory of Cardiovascular Research, IRCCS MultiMedica, Milan, Italy
}

\section{OPEN ACCESS}

Edited by: Nicolle Kraenkel,

Charité Medical University of Berlin, Germany

Reviewed by:

Martin Bahls,

Universitätsmedizin

Greifswald, Germany

Elena Osto,

University of Zurich, Switzerland Elisabeth Tamara Strässler,

Charité Medical University of Berlin, Germany Elisa Pagnin,

University of Padova, Italy

${ }^{*}$ Correspondence:

Paolo Madeddu mdprm@bristol.ac.uk

Specialty section This article was submitted to Cardiovascular Biologics and

Regenerative Medicine,

a section of the journa

Frontiers in Cardiovascular Medicine

Received: 14 June 2019 Accepted: 14 November 2019

Published: 27 November 2019

Citation:

Madeddu P, Avolio E, Alvino W, Santopaolo M and Spinetti G (2019)

Personalized Cardiovascular Regenerative Medicine: Targeting the Extreme Stages of Life.

Front. Cardiovasc. Med. 6:177. doi: 10.3389/fcvm.2019.00177
Cardiovascular regenerative medicine is an exciting new approach that promises to change the current care of million people world-wide. Major emphasis was given to the quality and quantities of regenerative products, but recent evidence points to the importance of a better specification of the target population that may take advantage of these advanced medical treatments. Patient stratification is an important step in drug development. Tailoring treatment to the patient's specificity allowed significant improvement in cancer therapy, but personalized regenerative medicine is still at the initial stage in the cardiovascular field. For example, new-borns with a congenital heart condition and elderly people require dedicated therapeutic approaches, which adapt to their lifetime needs. In these people, personalized treatments may overcome the benefits delivered by standard protocols. In this review, we provide insights into these extreme stages of life as potential targets for cardiovascular reconstitution.

\footnotetext{
Keywords: aging, regenerative, cardiovascular, stratification, personalized medicine, congenital heart disease, bone marrow, frailty
}

\section{INTRODUCTION}

Cardiovascular regenerative medicine promises to change the clinical outcome of million people. However, the translation from basic and preclinical research to the bedside has not maintained all the initial promises. Several reasons can account for these discrepancies, especially the need for further refinement of the drug or cell/gene product as well as the method and time of delivery. However, it is important to pay equal attention to the population that can take the maximum benefit from the new approach. Personalizing treatment for cardiovascular disease has had some remarkable successes in uncovering new therapeutic targets. For instance, the observation that inactivating mutations in the gene encoding the trafficking protein PCSK9 expose patients to a much lower risk for heart attacks fueled the development of antibody therapy targeting this protein. Other examples of cardiovascular drugs for which patient response is affected by the genetic makeup include warfarin and clopidogrel, used to prevent coagulation problems. A recent clinical trial with an antibody blocking the inflammatory cytokine IL- $1 \beta$ showed that individuals with high blood C-reactive protein (CRP) levels could take the maximum advantage for prevention of cardiovascular events (1).

Several biomarkers were proposed for improved prediction of the mode of action of stem cells in cardiac disease. These include markers of extracellular matrix remodeling, such as collagen degradation products, and inflammation, like TNF- $\alpha$ and CRP, which reflect continued immune dysfunction and oxidative damage in the myocardium. For instance, in the randomized TRIDENT 
trial (Transendocardial Stem Cell Injection Delivery Effects on Neomyogenesis), patients received transendocardial stem cell injection (TESI) of allogeneic mesenchymal stem cells (MSCs) at either a dose of 20 or 100 million cells (2). Results indicate that only those who received 100 million cells had improvements in left ventricular ejection fraction (LVEF), but both groups experienced a significant reduction in TNF- $\alpha$, both in the circulation and intracellular in B-cell, indicating the immunomodulatory effects of MSCs, which may play an important role in their improving cardiac function.

The importance of pretreatment assessment of contractility markers, such as the LVEF, in influencing the outcome of cell therapy remains controversial. Two recent meta-analyses of bone marrow cell therapy trials in patients with acute myocardial infarction (MI) indicate that patients experienced similar improvement in LVEF regardless of the baseline LVEF. However, improvements in left ventricular end-systolic volume were more pronounced in patients with lower baseline LVEF. In contrast, in trials of chronic myocardial ischemia, the increase in LVEF elicited by cell therapy was significant only in the group with lower LVEF at baseline $(3,4)$.

Current regenerative therapies are generally delivered to middle age populations, which show heterogeneous responses to therapies. Here, we overview evidence for personalized application of cardiovascular therapeutic approaches with emphasis on the two extreme stages of life: new-born and elderly.

\section{ADVANCED REGENERATIVE MEDICINE APPROACHES TO MEND THE NEWBORN HEART}

Congenital heart disease (CHD) is characterized by an abnormality in heart structure and is the most common type of birth defect, with a reported prevalence of 9 per 1,000 births $(5,6)$. Despite the progress in the surgical management of patients with $\mathrm{CHD}$, often solutions are temporary and only partially resolve the problem. Eventually, patients develop heart failure (HF) which contributes to high morbidity and mortality rates (7-9). In addition HF represents a major problem in the growing group of subjects that survive into adulthood, which are estimated to be 1.2 million in Europe only (10-12). HF is known to occur in $\approx 25 \%$ of adult CHD (ACHD) patients by the age of 30 , and the incidence increases with age (13). Therefore, new therapies should be developed to integrate current approaches of corrective cardiac surgery in newborns and infants with CHD.

\section{Conventional Treatment of Congenital Heart Disease}

The ideal cure for CHD consists of definitive surgical correction. In patients with Tetralogy of Fallot (ToF), a prototypical form of complex CHD, the aim is to relieve the obstruction to blood flow from the right ventricle (RV) to the pulmonary circulation and close the ventricular septum defect. Reconstruction of RV outflow tract (RVOT) involves resection of blocking muscle bundles and implantation of a prosthetic valve pulmonary conduit. Patients with complex CHD like TOF usually receive reconstructive surgery in infancy. Nevertheless, even full correction is not definitive. Re-interventions are necessary during a patient's life to substitute prostheses that become incompetent (14).

A spectrum of prostheses in the form of conduits, patches and valves is employed in congenital cardiac surgery, but none of them is perfect. Non-biological prostheses, like mechanical valves and Gore-Tex patches/conduits, have the advantage of high availability but do not possess growth potential (15). Moreover, mechanical valves require anticoagulation and can cause hemolysis. Biological prostheses, like autografts derived from patient's own valves/pericardium and pulmonary artery homografts from human cadavers, have excellent characteristics. However, their availability is limited. Therefore, to date, animalderived grafts (xenografts made with bovine or swine valvular, pericardial, or intestinal material) are the most common type of biological prostheses in reconstructive cardiac surgery. However, the manufacturing process makes grafts more prone to thrombosis and degeneration $(16,17)$.

In recent years, the need to overcome the above-mentioned limitations paved the way to a new, exciting medical-research field, namely tissue engineering.

\section{New Solutions From Stem Cell-Engineering}

Landmark clinical work has demonstrated the potential of biomaterials engineered with stem cells (SCs) for definitive correction of organ defects $(18,19)$. The approach has been proposed to improve the durability of cardiac prostheses and thereby optimize long-term outcomes in CHD patients (20, 21). The underlying concept is that incorporation of SCs shall confer prosthetic grafts with the characteristics of a living tissue that grows in a physiologic manner in parallel with cardiac and whole body growth and withstands the impact of degeneration (Figure 1) $(22,23)$. Initial experimental studies focused on preventing thrombotic complications by coating prosthetic valve leaflets with autologous endothelial cells (ECs)/endothelial progenitor cells (EPCs) (24). First-inhuman studies have provided initial evidence on feasibility and effective use of surface-enhanced valvular grafts $(25,26)$. However, to improve graft durability, additional aspects must be considered. (A) Cell-graft interactions. The main goals are for cells to: (i) colonize not only the surface but also the prosthesis core, (ii) survive and replicate to generate a stable resident population, (iii) dynamically synthesize ECM proteins in order to support graft stability and growth, and (iv) secrete factors favoring re-endothelialization, while preventing inflammation and calcification. These qualities are inherent to the cells, but also depend on proper interactions between the right cell and right prosthesis. Combining cells and prostheses already available in a clinical format may provide the means for swift exploitation, thus it may be advantageous to test them first. (B) Cell potency. Induced pluripotent SCs (iPSCs) generated by reprogramming somatic cells would be an ideal source for patient-specific therapy. However, recent reports have emphasized the pitfalls of iPSC technology, including the potential for genetic and epigenetic abnormalities, tumorigenicity, and immunogenicity (27). Hence, lineage-committed PCs remain a safer option thus 


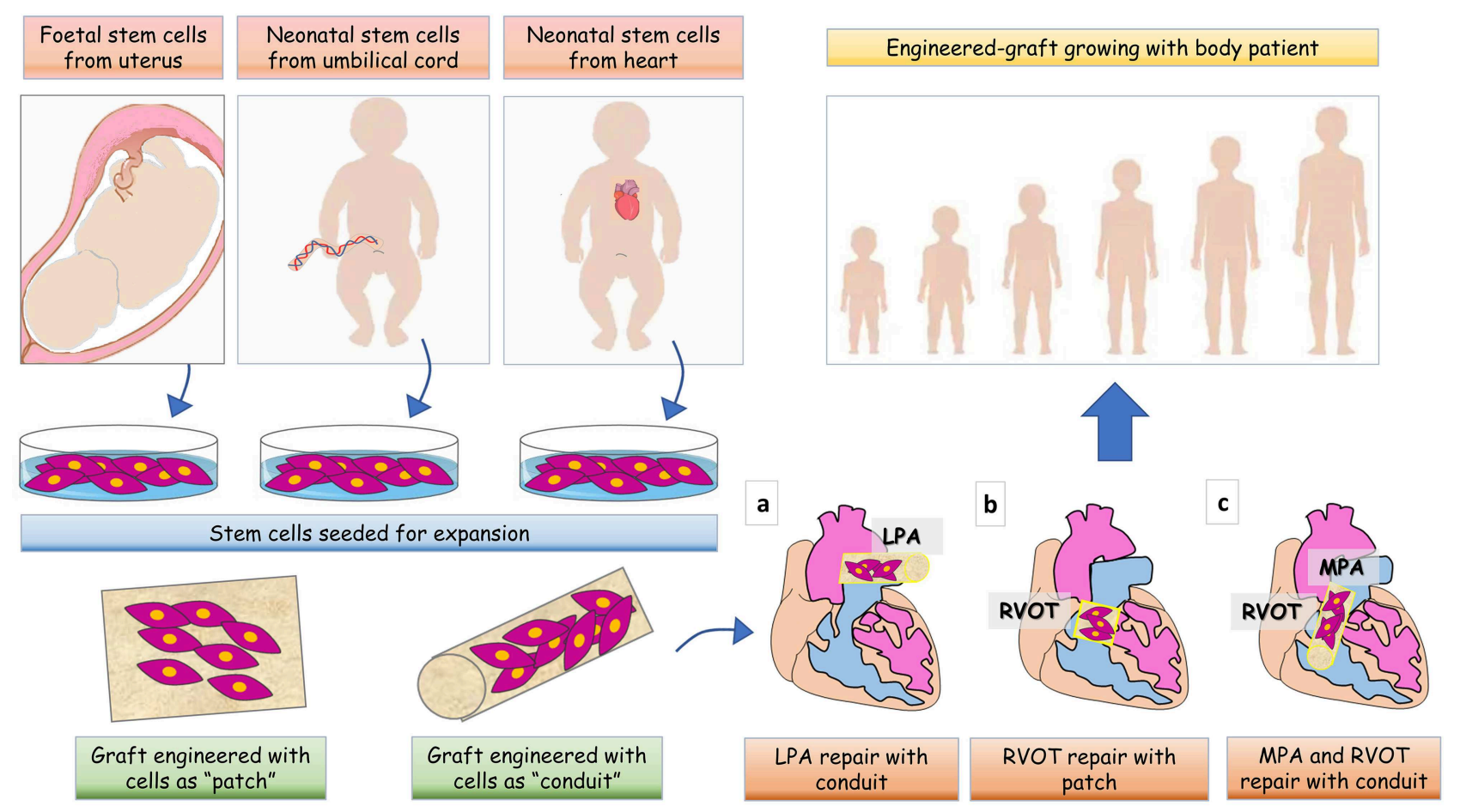

FIGURE 1 | Cartoon illustrating various tissue engineering strategies for full management of patients with CHD. Based on CHD diagnosis is made pre- or post-birth, stem cells can be collected from fetal tissues, umbilical cord or leftovers from palliative cardiac surgery. After collection, cells are expanded in vitro and seeded in a natural scaffold to generate a shaped patch- or conduit- graft to be implanted in the heart of CHD patients. The site of implantation of the graft is showed for (a) left pulmonary artery (LPA) reconstruction, (b) right ventricle outflow tract (RVOT) reconstruction, and (c) main pulmonary artery (MPA) and RVOT reconstruction.

far. (C) Cell accessibility and scalability. Thanks to advances of pre-natal cardiac imaging, it is now possible to recognize cardiac defects in utero and thus design tissue engineering applications for early primary correction. In this regard, fetal SCs could be obtained during an ongoing pregnancy (mid-trimester amniotic fluid or placenta specimens at the occasion of prenatal screening) or at baby delivery (placental or umbilical cord samples) (28-30).

Additionally, storage protocols of umbilical cord blood cells are well-established, thus allowing potential use for secondary correction. Recently, the Mayo Clinic announced the first trial with autologous umbilical cord blood cells to treat children with hypoplastic left heart syndrome, a defect in which the left ventricle is underdeveloped. SCs collected at birth are stored until intra-myocardial injection during secondary reconstructive surgery at 6 months of age (31).

Our group and others have reported that pericytes from human fetal hearts and aortas possess multilineage differentiation potential and vasculogenic activity in vitro and in vivo (3234). Extending those observations, we have set up a standard operating procedure (SOP) for expansion of pericytes from remnants of neonatal surgery. We are currently proposing the novel use of autologous cardiac pericytes collected during palliative surgery for cellularization of cardiac prostheses (35).

In conclusion, in the future this novel, personalized stem cellengineering approach promises to provide definitive solutions for the correction of CHD in the youngest patients.

\section{THE AGING POPULATION AND THE CLINICAL PROBLEM OF FRAILTY}

It is worth considering that in parallel to the steps forwards in the cure of early life cardiovascular dysfunction, the same regenerative strategies that are under consideration for the middle-aged population may not be effective for the growing number of elderly people. In fact, the progresses in medicine and the social modernization/secularization, in conjunction to the decrease in birth rate concur to the aging of the world population. At present, it is estimated that $16.1 \%$ of the European population is over the age of 65 years, and this number is predicted to rise to $22 \%$ by 2031 , which corresponds to approximately 137 million people $(36,37)$. This unprecedented demographic phenomenon is causing a great social and medical alarm, due to the expected increase of common diseases and geriatric syndromes, which often comprise more than one disorder at a time. Furthermore, many healthy older people become progressively unfit and incapable of handling life changes and stress, affected by the frailty syndrome. The term "geriatric frailty" was coined 30 years ago to define a clinical state in which there is an increase in an individual's vulnerability to adverse events and harm when exposed to a stressor. Primary frailty is not associated directly with a specific disease. However, in many instances, frailty is entwined with a pathological condition, like diabetes mellitus (DM) or osteoarthritis $(38,39)$. The Frailty Index estimates 23\% 
of people aged 65 or older is frail and has an increased risk of death. Furthermore, the presence of frailty increases the risk of death attributable to an associated disease. For instance, a 12year follow-up study conducted on more than 1,200 patients showed a strong synergic effect of frailty and osteoarthritis on life expectancy (40). Frail population demands high medical and social care, absorbing a significant amount of resources from the national health systems.

\section{Bone Marrow Stem Cell Frailty: A Model to Reinterpret Whole Body Vulnerability}

Novel experimental and clinical evidence indicates that the status of the bone marrow (BM) predicts the global outcome of vulnerable patients. The BM is the main reservoir of SCs in adulthood. We believe that its status and the function of cells released from BM into the circulation can reflect the general regenerative capacity of the human body.

Our team has demonstrated that DM, which is frequently associated with frailty $(38,39)$, causes a profound BM remodeling in mice and humans, with reduction of the hematopoietic tissue, microvascular rarefaction, adipose tissue accumulation, and osteoporosis. Also, we showed that hematopoietic SC (HSC) depletion was associated with increased oxidative stress, DNA damage, and activation of apoptosis (41). Furthermore, oxidative stress was responsible for an alteration of the BM vascular barrier function, contributing to stem cell mobilopathy (42). Landmark work from Fadini demonstrates that levels of circulating proangiogenic progenitor cells inversely correlate with classical cardiovascular risk factors and atherosclerotic complications in the coronary, peripheral and cerebrovascular districts. Another fundamental study in a large population with coronary artery disease showed that reduced circulating progenitor cell counts, identified primarily as CD34 ${ }^{\text {pos }}$ cells, are associated with risk of death (43). A definitive meta-analysis of 21 studies, comprising 4,155 individuals, confirmed this association (44). Together with the notion that CD34 ${ }^{\text {pos }}$ progenitor cells maintain cardiovascular health, these studies suggest that an impaired liberation of reparative cells from BM to the circulation contribute to promoting cardiovascular vulnerability (45). HSCs could also transfer harmful signals to the peripheral vasculature. In this way, potentially restoring responses afforded by BM-derived reparative cells could be transformed into a dangerous phenomenon. This raises the possibility of developing assays based on circulating cells for prediction of longterm cardiovascular outcomes and eventually, new therapies intercepting downstream signaling pathways. A few years ago, we started a prospective study investigating if the abundance and migratory activity of a subpopulation of circulating mononuclear cells, namely, $\mathrm{CD} 45^{\mathrm{dim}} \mathrm{CD} 34^{\text {pos }} \mathrm{CXCR} 4{ }^{\text {pos }} \mathrm{KDR}^{\text {pos }}$ cells, predict major amputation and cardiovascular death in type 2 diabetic patients undergoing percutaneous transluminal angioplasty for critical limb ischemia. Multivariable regression model analysis at 18 months follow-up showed that in vitro cell migration forecasts cardiovascular mortality independently of other validated predictors, such as age, diagnosed coronary artery disease, serum CRP, and estimated glomerular filtration rate. In this model, doubling of migrated cell counts increases the cardiovascular death hazard by $100 \%$ (46). We have now confirmed the value of the predictor at 6 years follow-up and also identified a potential molecular target responsible for circulating cells to cause endothelial cell damage and death (Madeddu and Spinetti, unpublished data).

Mechanistic studies indicate that aging and DM contribute in impairing stem cell/progenitor cell mobilization via dysregulation of the key lifespan determinant pathway comprising the silent information regulator (SIR)T1, p66Shc, and mammalian target of rapamycin (mTOR) (47-49). These genes integrate longevity pathways and metabolic signals in a complex interplay in which lifespan appears to be strictly dependent on substrate and energy bioavailability (50). Recent data from Fadini's group indicates that cell-autonomous activation of the Oncostatin M (OSM)-p66Shc pathway leads to DM-associated myelopoiesis, whereas its transcellular hematostromal activation links myelopoiesis to mobilopathy. Therefore, targeting the OSM-p66Shc pathway may represent a novel strategy to disconnect mobilopathy from myelopoiesis and restore normal stem cell mobilization (51).

A large body of evidence indicates the implication of microRNAs in stem cell senescence and vulnerability. We have documented that DM remarkably alters the expression of microRNAs implicated in the control of hematopoiesis and vasculogenesis. In a cohort of subjects undergoing hip replacement for arthrosis, we showed that DM downregulates the microRNA-155 in BM HSCs, which results in induction of HSC apoptosis via induction of the target gene Forkhead Box O3a (FOXO3a) and cell cycle controllers p21 and p27kip1 (52). P21 and p27kip1 inhibit cell cycle progression by binding to, and inactivating, cyclin-dependent kinase complexes. Analysis of cell cycle by flow cytometry confirmed that CD34 ${ }^{\text {pos }}$ cells from diabetic BM are stalled at the G1 checkpoint and undergo apoptosis with high frequency. Furthermore, we demonstrated the upregulation of several anti-angiogenic microRNAs, such as microRNA-15, 16, and 503, in circulating pro-angiogenic cells from patients with ischemic complications $(52,53)$.

Of note, BM HSCs accumulate mutations during aging in specific genes that lead to the generation of clonal leukocytes in the peripheral blood harboring a $2 \%$ variant allele fraction. These mutations occur in genes usually associated to acute myeloid leukemia or myelodysplastic syndrome but confer a low risk (0.5$1 \%$ per year) of developing neoplasms. This condition in the absence of morphological indication of a tumor is referred as clonal hematopoiesis of indeterminate potential (CHIP). Since CHIP carrier have an increased risk of all-cause mortality and worsen heart failure estimated to be $40 \%$, it is clear that this risk factor will have to be taken into consideration in future patient stratification strategies in the elderly (54-56).

\section{Restoring BM Health in Vulnerable Individuals}

Evidence from our group and others have shown that age- and DM-related BM stem cell dysfunction can be reversed by using nutritional supplements and physical exercise, both interventions exerting a salutary effect through a reduction in oxidative stress and activation of pro-survival pathways $(41,49,57)$. For instance, both acute and regular exercise have been associated to increase number of circulating progenitor cells via modulation 
of mobilizing factors such as the duo CXCL12/CXCR4, VEGFA, MMPs, and nitric oxide (57). Moreover, we demonstrated the feasibility of reversing the BM pathology by dietary supplementation of benfotiamine, a vitamin B1 analog and an activator of the pentose phosphate pathway, which represents a fundamental source of antioxidant equivalents and substrates for DNA synthesis and repair. These interventions are more effective if inserted in a preventive program. Therefore, recognition of early stage of frailty is of pivotal importance to avoid residual repair potential is exhausted, which may result in therapeutic failure. We are currently exploring if the assessment of BMderived circulating proangiogenic cells could be a marker of accruing cardiovascular frailty.

Caloric restriction has been reported the most powerful intervention to retard aging and increase longevity in several species. Studies in humans have confirmed the effect of caloric restriction on the reduction of early signs of cardiovascular diseases and cognitive decline $(58,59)$. Indeed, caloric intake controls a broad range of functions and modifications of caloric intake elicit several systemic and cellular responses, including mitochondrial bioenergetics.

Although several signaling pathways have been associated with the effect of caloric restriction on age-associated changes and on longevity (e.g., AMPK pathway, IGF-1-like growth factor, TOR, SIRT-1, among the most known), targeting these systems did not recapitulate all the beneficial effects of diet pointing to still unknown mechanisms (60).

It will be invaluable to determine if caloric restriction exerts therapeutic benefits in frail patients.

\section{FUTURE DIRECTIONS}

The recognition of patients' specificity for tailoring more effective regenerative treatments opens new avenues to clinical

\section{REFERENCES}

1. Ridker PM, Thuren T, Zalewski A, Libby P. Interleukin-1beta inhibition and the prevention of recurrent cardiovascular events: rationale and design of the Canakinumab Anti-inflammatory Thrombosis Outcomes Study (CANTOS). Am Heart J. (2011) 162:597-605. doi: 10.1016/j.ahj.2011. 06.012

2. Florea V, Rieger AC, DiFede DL, El-Khorazaty J, Natsumeda M, Banerjee $\mathrm{MN}$, et al. Dose comparison study of allogeneic mesenchymal stem cells in patients with ischemic cardiomyopathy (The TRIDENT Study). Circ Res. (2017) 121:1279-90. doi: 10.1161/CIRCRESAHA.117.311827

3. Afzal MR, Samanta A, Shah ZI, Jeevanantham V, Abdel-Latif A, Zuba-Surma EK, et al. Adult bone marrow cell therapy for ischemic heart disease: evidence and insights from randomized controlled trials. Circ Res. (2015) 117:558-75. doi: 10.1161/CIRCRESAHA.114.304792

4. Brunskill SJ, Hyde CJ, Doree CJ, Watt SM, Martin-Rendon E. Route of delivery and baseline left ventricular ejection fraction, key factors of bone-marrowderived cell therapy for ischaemic heart disease. Eur J Heart Fail. (2009) 11:887-96. doi: 10.1093/eurjhf/hfp101

5. Dolk H, Loane M, Garne E, European Surveillance of Congenital Anomalies Working G. Congenital heart defects in Europe: prevalence and perinatal mortality, 2000 to 2005. Circulation. (2011) 123:841-9. doi: 10.1161/CIRCULATIONAHA.110.958405 exploitation. This endeavor will be certainly helped by concomitant advances in cardiovascular imaging and mechanistic -omics investigation that will increase the current knowledge that we have, at least in part, described in this article. The enormous quantities of new data derived from these approaches will require increased use of computing systems. Artificial Intelligence is a technological tool capable of analyzing and inter-linking voluminous data by scanning for appropriate relationships. Companies are already training algorithms of million clinical data points from images of coronary arteries and creating intelligent platforms that can learn to detect coronary artery disease using pattern recognition. A similar approach uses coronary calcium scoring to predict a patient's risk. These platforms could be integrated with molecular data on the regenerative potential of an individual leading to the development of predictive models for personalized treatments with pharmacological rejuvenation, or exogenous application of engineered stem cells, therapeutic genes and regenerative tissue. Less invasive surgical procedures will also be key to implant advanced regenerative products improving the quality of life of the very young and elderly.

\section{AUTHOR CONTRIBUTIONS}

All authors listed have made a substantial, direct and intellectual contribution to the work, and approved it for publication.

\section{FUNDING}

This work has been supported by grants from the British Heart Foundation to PM (BHF Centre for Vascular Regeneration $\mathrm{RM} / 17 / 3 / 33381$ ), and the Italian Ministry of Health Ricerca Corrente and the Cariplo Foundation (Rif 2016-0922) to the IRCCS MultiMedica.
6. Sun R, Liu M, Lu L, Zheng Y, Zhang P. Congenital heart disease: causes, diagnosis, symptoms, and treatments. Cell Biochem Biophys. (2015) 72:85760. doi: 10.1007/s12013-015-0551-6

7. Rossano JW, Shaddy RE. Heart failure in children: etiology and treatment. $J$ Pediatr. (2014) 165:228-33. doi: 10.1016/j.jpeds.2014.04.055

8. Massin MM, Astadicko I, Dessy H. Epidemiology of heart failure in a tertiary pediatric center. Clin Cardiol. (2008) 31:388-91. doi: 10.1002/clc.20262

9. Sommers C, Nagel BH, Neudorf U, Schmaltz AA. Congestive heart failure in childhood. An epidemiologic study. Herz. (2005) 30:652-62. doi: 10.1007/s00059-005-2596-6

10. Konstam MA, Kiernan MS, Bernstein D, Bozkurt B, Jacob M, Kapur NK, et al. Evaluation and management of right-sided heart failure: a scientific statement from the american heart association. Circulation. (2018) 137:e578e622. doi: 10.1161/CIR.0000000000000560

11. Hinton RB, Ware SM. Heart failure in pediatric patients with congenital heart disease. Circ Res. (2017) 120:978-94. doi: 10.1161/CIRCRESAHA.116.308996

12. Best KE, Rankin J. Long-term survival of individuals born with congenital heart disease: a systematic review and meta-analysis. J Am Heart Assoc. (2016) 5:e002846. doi: 10.1161/JAHA.115.002846

13. Norozi K, Wessel A, Alpers V, Arnhold JO, Geyer S, Zoege M, et al. Incidence and risk distribution of heart failure in adolescents and adults with congenital heart disease after cardiac surgery. Am J Cardiol. (2006) 97:1238-43. doi: 10.1016/j.amjcard.2005.10.065 
14. Said SM, Burkhart HM. When repair is not feasible: prosthesis selection in children and adults with congenital heart disease. Semin Thorac Cardiovasc Surg Pediatr Card Surg Annu. (2014) 17:22-9. doi: 10.1053/j.pcsu.2014.01.002

15. Allen BS, El-Zein C, Cuneo B, Cava JP, Barth MJ, Ilbawi MN. Pericardial tissue valves and Gore-Tex conduits as an alternative for right ventricular outflow tract replacement in children. Ann Thorac Surg. (2002) 74:771-7. doi: 10.1016/S0003-4975(02)03767-0

16. Rieder E, Kasimir MT, Silberhumer G, Seebacher G, Wolner E, Simon P, et al. Decellularization protocols of porcine heart valves differ importantly in efficiency of cell removal and susceptibility of the matrix to recellularization with human vascular cells. J Thorac Cardiovasc Surg. (2004) 127:399-405. doi: 10.1016/j.jtcvs.2003.06.017

17. Tudorache I, Cebotari S, Sturz G, Kirsch L, Hurschler C, Hilfiker A, et al. Tissue engineering of heart valves: biomechanical and morphological properties of decellularized heart valves. J Heart Valve Dis. (2007) 16:567-73; discussion: 574

18. Macchiarini P, Jungebluth P, Go T, Asnaghi MA, Rees LE, Cogan TA, et al. Clinical transplantation of a tissue-engineered airway. Lancet. (2008) 372:2023-30. doi: 10.1016/S0140-6736(08)61598-6

19. Badylak SF, Weiss DJ, Caplan A, Macchiarini P. Engineered whole organs and complex tissues. Lancet. (2012) 379:943-52. doi: 10.1016/S0140-6736(12)60073-7

20. Bernstein HS, Srivastava D. Stem cell therapy for cardiac disease. Pediatr Res. (2012) 71:491-9. doi: 10.1038/pr.2011.61

21. Pincott ES, Burch M. Potential for stem cell use in congenital heart disease. Future Cardiol. (2012) 8:161-9. doi: 10.2217/fca.12.13

22. Scholl FG, Boucek MM, Chan KC, Valdes-Cruz L, Perryman R. Preliminary experience with cardiac reconstruction using decellularized porcine extracellular matrix scaffold: human applications in congenital heart disease. World J Pediatr Congen Heart Surg. (2010) 1:132-6. doi: $10.1177 / 2150135110362092$

23. Bertipaglia B, Ortolani F, Petrelli L, Gerosa G, Spina M, Pauletto P, et al. Cell characterization of porcine aortic valve and decellularized leaflets repopulated with aortic valve interstitial cells: the VESALIO Project (Vitalitate Exornatum Succedaneum Aorticum Labore Ingenioso Obtenibitur). Ann Thorac Surg. (2003) 75:1274-82. doi: 10.1016/S0003-4975(02)04706-9

24. Hibino N, McGillicuddy E, Matsumura G, Ichihara Y, Naito Y, Breuer C, et al. Late-term results of tissue-engineered vascular grafts in humans. J Thoracic Cardiovasc Surg. (2010) 139:431-6; 436 e1-2. doi: 10.1016/j.jtcvs.2009. 09.057

25. Cebotari S, Tudorache I, Schilling T, Haverich A. Heart valve and myocardial tissue engineering. Herz. (2010) 35:334-41. doi: 10.1007/s00059-010-3355-x

26. Dohmen PM, Lembcke A, Holinski S, Pruss A, Konertz W. Ten years of clinical results with a tissue-engineered pulmonary valve. Ann Thorac Surg. (2011) 92:1308-14. doi: 10.1016/j.athoracsur.2011.06.009

27. Okano H, Nakamura M, Yoshida K, Okada Y, Tsuji O, Nori S, et al. Steps toward safe cell therapy using induced pluripotent stem cells. Circ Res. (2013) 112:523-33. doi: 10.1161/CIRCRESAHA.111.256149

28. Wu KH, Mo XM, Zhou B, Lu SH, Yang SG, Liu YL, et al. Cardiac potential of stem cells from whole human umbilical cord tissue. J Cell Biochem. (2009) 107:926-32. doi: 10.1002/jcb.22193

29. Chen MY, Lie PC, Li ZL, Wei X. Endothelial differentiation of Wharton's jelly-derived mesenchymal stem cells in comparison with bone marrowderived mesenchymal stem cells. Exp Hematol. (2009) 37:629-40. doi: 10.1016/j.exphem.2009.02.003

30. Klemmt PA, Vafaizadeh V, Groner B. The potential of amniotic fluid stem cells for cellular therapy and tissue engineering. Expert Opin Biol Ther. (2011) 11:1297-314. doi: 10.1517/14712598.2011.587800

31. Bittle GJ, Morales D, Deatrick KB, Parchment N, Saha P, Mishra R, et al. Stem cell therapy for hypoplastic left heart syndrome: mechanism, clinical application, and future directions. Circ Res. (2018) 123:288-300. doi: 10.1161/CIRCRESAHA.117.311206

32. Invernici G, Emanueli C, Madeddu P, Cristini S, Gadau S, Benetti A, et al. Human fetal aorta contains vascular progenitor cells capable of inducing vasculogenesis, angiogenesis, and myogenesis in vitro and in a murine model of peripheral ischemia. Am J Pathol. (2007) 170:1879-92. doi: 10.2353/ajpath.2007.060646
33. Chen WC, Baily JE, Corselli M, Diaz ME, Sun B, Xiang G, et al. Human myocardial pericytes: multipotent mesodermal precursors exhibiting cardiac specificity. Stem Cells. (2015) 33:557-73. doi: 10.1002/stem.1868

34. Barcelos LS, Duplaa C, Krankel N, Graiani G, Invernici G, Katare $\mathrm{R}$, et al. Human $\mathrm{CD} 133+$ progenitor cells promote the healing of diabetic ischemic ulcers by paracrine stimulation of angiogenesis and activation of Wnt signaling. Circ Res. (2009) 104:1095-102. doi: 10.1161/CIRCRESAHA.108.192138

35. Avolio E, Rodriguez-Arabaolaza I, Spencer HL, Riu F, Mangialardi G, Slater SC, et al. Expansion and characterization of neonatal cardiac pericytes provides a novel cellular option for tissue engineering in congenital heart disease. J Am Heart Assoc. (2015) 4:e002043. doi: 10.1161/JAHA.115.002043

36. Fleg JL, Aronow WS, Frishman WH. Cardiovascular drug therapy in the elderly: benefits and challenges. Nat Rev Cardiol. (2011) 8:13-28. doi: $10.1038 /$ nrcardio.2010.162

37. Heidenreich PA, Trogdon JG, Khavjou OA, Butler J, Dracup K, Ezekowitz $\mathrm{MD}$, et al. Forecasting the future of cardiovascular disease in the United States: a policy statement from the American Heart Association. Circulation. (2011) 123:933-44. doi: 10.1161/CIR.0b013e31820a55f5

38. Ottenbacher KJ, Graham JE, Al Snih S, Raji M, Samper-Ternent R, Ostir GV, et al. Mexican Americans and frailty: findings from the Hispanic established populations epidemiologic studies of the elderly. Am J Public Health. (2009) 99:673-9. doi: 10.2105/AJPH.2008.143958

39. Hubbard RE, Andrew MK, Fallah N, Rockwood K. Comparison of the prognostic importance of diagnosed diabetes, co-morbidity and frailty in older people. Diabet Med. (2010) 27:603-6. doi: 10.1111/j.1464-5491.2010.02977.x

40. Cacciatore F, Della-Morte D, Basile C, Mazzella F, Mastrobuoni C, Salsano $\mathrm{E}$, et al. Long-term mortality in frail elderly subjects with osteoarthritis. Rheumatology. (2014) 53:293-9. doi: 10.1093/rheumatology/ket348

41. Oikawa A, Siragusa M, Quaini F, Mangialardi G, Katare RG, Caporali A, et al. Diabetes mellitus induces bone marrow microangiopathy. Arterioscler Thromb Vasc Biol. (2010) 30:498-508. doi: 10.1161/ATVBAHA.109.200154

42. Mangialardi G, Katare R, Oikawa A, Meloni M, Reni C, Emanueli C, et al. Diabetes causes bone marrow endothelial barrier dysfunction by activation of the RhoA-Rho-associated kinase signaling pathway. Arterioscler Thromb Vasc Biol. (2013) 33:555-64. doi: 10.1161/ATVBAHA.112.300424

43. Patel RS, Li QN, Ghasemzadeh N, Eapen DJ, Moss LD, Janjua AU, et al. Circulating CD34(+) progenitor cells and risk of mortality in a population with coronary artery disease. Circul Res. (2015) 116:289-297. doi: 10.1161/CIRCRESAHA.116.304187

44. Rigato M, Avogaro A, Fadini GP. Levels of circulating progenitor cells, cardiovascular outcomes and death: a meta-analysis of prospective observational studies. Circ Res. (2016) 118:1930-9. doi: 10.1161/CIRCRESAHA.116.308366

45. Fadini GP, Losordo D, Dimmeler S. Critical reevaluation of endothelial progenitor cell phenotypes for therapeutic and diagnostic use. Circul Res. (2012) 110:624-37. doi: 10.1161/CIRCRESAHA.111.243386

46. Spinetti G, Specchia C, Fortunato O, Sangalli E, Clerici G, Caminiti M, et al. Migratory activity of circulating mononuclear cells is associated with cardiovascular mortality in type 2 diabetic patients with critical limb ischemia. Diabetes Care. (2014) 37:1410-7. doi: 10.2337/dc13-2084

47. Amadesi S, Reni C, Katare R, Meloni M, Oikawa A, Beltrami AP, et al. Role for substance p-based nociceptive signaling in progenitor cell activation and angiogenesis during ischemia in mice and in human subjects. Circulation. (2012) 125:1774-86; S1-19. doi: 10.1161/CIRCULATIONAHA.111. 089763

48. Dang Z, Maselli D, Spinetti G, Sangalli E, Carnelli F, Rosa F, et al. Sensory neuropathy hampers nociception-mediated bone marrow stem cell release in mice and patients with diabetes. Diabetologia. (2015) 58:2653-62. doi: 10.1007/s00125-015-3735-0

49. Albiero M, Poncina N, Tjwa M, Ciciliot S, Menegazzo L, Ceolotto G, et al. Diabetes causes bone marrow autonomic neuropathy and impairs stem cell mobilization via dysregulated p66Shc and Sirt1. Diabetes. (2014) 63:1353-65. doi: $10.2337 / \mathrm{db} 13-0894$

50. Fadini GP, Ceolotto G, Pagnin E, de Kreutzenberg S, Avogaro A. At the crossroads of longevity and metabolism: the metabolic syndrome 
and lifespan determinant pathways. Aging Cell. (2011) 10:10-7. doi: 10.1111/j.1474-9726.2010.00642.x

51. Albiero M, Ciciliot S, Tedesco S, Menegazzo L, D'Anna M, Scattolini $\mathrm{V}$, et al. Diabetes-associated myelopoiesis drives stem cell mobilopathy through an OSM-p66Shc signaling pathway. Diabetes. (2019) 68:1303-14. doi: $10.2337 / \mathrm{db} 19-0080$

52. Spinetti G, Fortunato O, Caporali A, Shantikumar S, Marchetti M, Meloni $\mathrm{M}$, et al. MicroRNA-15a and microRNA-16 impair human circulating proangiogenic cell functions and are increased in the proangiogenic cells and serum of patients with critical limb ischemia. Circ Res. (2013) 112:335-46. doi: 10.1161/CIRCRESAHA.111.300418

53. Caporali A, Meloni M, Vollenkle C, Bonci D, Sala-Newby GB, Addis $\mathrm{R}$, et al. Deregulation of microRNA-503 contributes to diabetes mellitus-induced impairment of endothelial function and reparative angiogenesis after limb ischemia. Circulation. (2011) 123:282-91. doi: 10.1161/CIRCULATIONAHA.110.952325

54. Jaiswal S, Fontanillas P, Flannick J, Manning A, Grauman PV, Mar BG, et al. Age-related clonal hematopoiesis associated with adverse outcomes. $\mathrm{N} \mathrm{Engl} \mathrm{J}$ Med. (2014) 371:2488-98. doi: 10.1056/NEJMoa1408617

55. Dorsheimer L, Assmus B, Rasper T, Ortmann CA, Ecke A, Abou-El-Ardat $\mathrm{K}$, et al. Association of mutations contributing to clonal hematopoiesis with prognosis in chronic ischemic heart failure. JAMA Cardiol. (2019) 4:25-33. doi: 10.1001/jamacardio.2018.3965

56. Libby P, Sidlow R, Lin AE, Gupta D, Jones LW, Moslehi J, et al. Clonal hematopoiesis: crossroads of aging, cardiovascular disease, and cancer:
JACC review topic of the week. J Am Coll Cardiol. (2019) 74:567-77. doi: 10.1016/j.jacc.2019.06.007

57. Ross MD, Malone E, Florida-James G. Vascular ageing and exercise: focus on cellular reparative processes. Oxid Med Cell Longev. (2016) 2016:3583956. doi: $10.1155 / 2016 / 3583956$

58. Willcox DC, Willcox BJ, Todoriki H, Curb JD, Suzuki M. Caloric restriction and human longevity: what can we learn from the Okinawans? Biogerontology. (2006) 7:173-7. doi: 10.1007/s10522-006-9008-z

59. Noyan H, El-Mounayri O, Isserlin R, Arab S, Momen A, Cheng HS, et al Cardioprotective signature of short-term caloric restriction. PLOS ONE. (2015) 10:e0130658. doi: 10.1371/journal.pone.0130658

60. Kenyon CJ. The genetics of ageing. Nature. (2010) 464:504-12. doi: 10.1038 /nature08980

Conflict of Interest: The authors declare that the research was conducted in the absence of any commercial or financial relationships that could be construed as a potential conflict of interest.

Copyright (อ 2019 Madeddu, Avolio, Alvino, Santopaolo and Spinetti. This is an open-access article distributed under the terms of the Creative Commons Attribution License (CC BY). The use, distribution or reproduction in other forums is permitted, provided the original author(s) and the copyright owner(s) are credited and that the original publication in this journal is cited, in accordance with accepted academic practice. No use, distribution or reproduction is permitted which does not comply with these terms. 